\title{
ОСОБЕННОСТИ ЭТИОЛОГИИ ВНЕБОЛЬНИЧНЫХ ПНЕВМОНИЙ, АССОЦИИРОВАННЫХ С COVID-19
}

А.Ю. Попова ${ }^{1,2}$, Е.Б. Ежлова ${ }^{1}$, Ю.В. Демина ${ }^{1,2}$, А.К. Носков ${ }^{3}$, Е.В. Ковалев ${ }^{4}$, О.С. Чемисова ${ }^{3}$, Т.И. Твердохлебова ${ }^{5}$, Н.В. Павлович ${ }^{3}$, С.О. Водопьянов ${ }^{3}$, М.В. Цимбалистова ${ }^{3}$, Н.Е. Гаевская ${ }^{3}$, С.Ф. Воловикова ${ }^{3}$ С.И. Стенина ${ }^{3}$, Е.Н. Гудуева ${ }^{3}$, М.М. Сагакянц ${ }^{3}$, А.В. Алешукина ${ }^{5}$, С.С. Слись ${ }^{4}$

${ }^{1}$ Федеральная служба по надзору в сфере защиты прав потребителей и благополучия человека, Москва, Россия

${ }^{2}$ Российская медицинская академия непрерывного профессионального образования, Москва, Российская Федерация

${ }^{3}$ Федеральное казенное учреждение здравоохранения «Ростовский-на-Дону противочумный институт» Федеральной службы по надзору в сфере защиты прав потребителей и благополучия человека, Ростов-на-Дону, Россия

${ }^{4}$ Управление Роспотребнадзора по Ростовской области, Ростов-на-Дону, Россия

${ }^{5}$ Федеральное бюджетное учреждение науки «Ростовский научно-исследовательский институт микробиологии и паразитологии» Федеральной службы по надзору в сфере защиты прав потребителей и благополучия человека, Ростов-на-Дону, Россия

\section{Резюме}

Представлены результаты исследования этиологических агентов бактериальной и вирусной природы у пациентов с диагнозом внебольничная пневмония, ассоциированной с COVID-19. В период распространения новой коронавирусной инфекции в Ростовской области основным этиологическим агентом внебольничных пневмоний является новый коронавирус SARS-CoV-2. Особенностью ВП у пациентов с лабораторно подтвержденным COVID-19 является более высокая частота микст-инфекций как вирусной, так и бактериальной этиологии. На фоне выявления у пациентов с ВП PHK SARS-CoV-2 зарегистрированы случаи обнаружения коронавирусов других типов (HKU-1,OC43, HL-63 или 229E). Наиболее часто этиологическим агентом ВП бактериальной природы у пациентов являлись бактерии рода Streptococcus как у пациентов с ВП, ассоциированной с COVID-19, так и у пациентов с отрицательным результатом на SARS-CoV-2.

Ключевые слова: COVID-19, внебольничная пневмония, виды бактерий, респираторные вирусы, Ростовская область.

Корреспондирующий автор: Алексей Кимович Носков, e-mail: noskov-epid@mail.ru. 
Внебольничные пневмонии (ВП) представляют серьезную проблему инфекционной патологии человека и являются одной из ведущих причин смерти от инфекционных болезней. Внебольничная пневмония - острое заболевание, возникшее во внебольничных условиях (вне стационара или позднее 4 недель после выписки из него), сопровождающееся симптомами инфекции нижних отделов дыхательных путей [1]. Согласно данным официальной статистики, заболеваемость ВП в РФ в 2018 г. составила 492,2 на 100 тыс. населения, что на 19,1 \% выше по сравнению с 2017 годом [2]. Ведущими возбудителями ВП являются Streptococcus pneumoniae, Haemophilus influenzae, бактерии семейства Enterobacteriaceae - Klebsiella pneumoniae, Escherichia coli и др., Staphylococcus aureus [1]. K известным атипичным бактериальным возбудителям ВП относятся такие микроорганизмы, как Mycoplasma pneumoniae, Chlamydophila pneumoniae, Legionella pneumophila, Chlamydophila psittaci и Coxiella burnetii [3]. Такие условно патогенные бактерии представители резидентной микрофлоры носоглотки человека, как Streptococcus viridans, коагулазанегативные стафилококки, Enterococcus spp., Neisseria spp., Candida spp. могут иметь этиологическое значение только при их неконтролируемом размножении на фоне резкого снижения иммунного статуса организма. Их выделение в незначительных количествах из мокроты у пациентов без выраженного иммунодефицита с высокой степенью вероятности может свидетельствовать о контаминации материала микрофлорой верхних отделов дыхательных путей. Возбудителями ВП могут быть и респираторные вирусы, наиболее часто - вирусы гриппа, коронавирусы, риносинцитиальный вирус (РС-вирус), метапневмовирус и бокавирус человека [1]. При ВП может иметь место коинфекция двумя и более возбудителями, вызванная как ассоциацией различных бактериальных возбудителей, так и их сочетанием с респираторными вирусами. Частота встречаемости ВП, вызванной ассоциацией возбудителей, варьирует от 3 до 40\% [4].

Пандемия новой коронавирусной инфекции сопровождается высоким уровнем заболеваемости ВП, с высокой долей осложненных и затяжных случаев. Известно, что вирусы вызывают нарушения работы иммунной системы, что делает людей более восприимчивыми к другим патогенам [5]. G. Zahariadis с соавт. в 2006 году, основываясь на результатах серологических исследований пациентов, перенесших ОРВИ, выявили случаи острой или недавней инфекции C. pneumoniae (30\%) или M. pneumoniae (9\%) [6]. Многоцентровое ретроспективное когортное исследование пациентов с тяжелым течением Ближневосточного респираторного синдрома, вызванного коронавирусом (БВРС-КоВ), показало, что 18\% и 5\% имели бактериальные и вирусные коинфекции соответственно [7]. 
Предыдущие исследования показали, что коронавирус наносит серьезный удар по иммунной системе человека. Например, одним из наиболее распространенных симптомов у пациентов с COVID-19 является временное или стойкое снижение уровня лимфоцитов в крови. Разрушение иммунных клеток вирусом SARS-CoV-2 делает пациентов уязвимыми к вторичным бактериальным инфекциям. Пневмония у пациентов с COVID-19 отличается от SARS-CoV-2-негативной внебольничной пневмонии [8].

Chih-Cheng Lai с соавт. (2020 г.) провели анализ лабораторных данных о вторичных инфекциях при COVID-19, опубликованных исследователями Китая, США, Сингапура и Италии. При обследовании 18-ти пациентов в Сингапуре ни у одного из них не было сопутствующих или вторичных инфекций. Напротив, результаты исследовательских групп выявили распространенность вторичных осложнений, ассоциированных с COVID-19, частота которых колебалась от 0,6\% до 45,0\%. В других шести независимых исследованиях были зарегистрированы осложнения, обусловленные присоединением бактериальной коинфекции, этиологические агенты которых включали $M$. pneumoniae, L. pneumophila, S. pneumoniae и K. pneumoniae. В литературе имеются также сообщения о вирусных сопутствующих коинфекциях; риновирус/энтеровирус и грипп А были наиболее распространенными ассоциантами. Кроме того, в качестве сопутствующих патогенов были зарегистрированы коронавирус, респираторно-синцитиальный вирус, парагрипп, метапневмовирус и вирус гриппа В [9]. В работе Chen et al. (2020 г.) в исследовании 99 COVID-19 пациентов, 4 (4,0\%) имели грибковые сопутствующие инфекции, включая Candida albicans и Candida glabrata [10]. Стуловой М.В. с соавт. (2020 г.) при исследовании пациентов с ВП, ассоциированной с COVID-19, наиболее частыми бактериальными агентами были определены S. pneumoniae (70,0\%), Streptococcus agalactiae (10,0\%), S. pneumoniae + S. aureus (6,6\%), S. pneumoniae + Pseudomonas aeruginosa (13,3\%) [11].

В Ростовской области по данным Управления Роспотребнадзора по Ростовской области за первые 7 месяцев 2020 зарегистрирован 13621 случай ВП - 324,1 на 100 тыс. населения, что в 1,8 раза выше аналогичного периода 2019 года, и выше среднемноголетнего уровня в 1,8 раза. За 7 месяцев 2020 года 253 пневмонии завершились летальным исходом (7 месяцев 2019 - 36 летальных), показатель увеличился в 7,1 раза (6,0 против 0,9), у всех имелся отягощенный преморбидный фон - ишемическая болезнь сердца, сахарный диабет, ожирение, алкоголизм и т.д., в 225 случаях получено подтверждение COVID-19, что составляет 88,9 \% от всех летальных случаев внебольничной пневмонии текущего года.

Неотъемлемой частью диагностики ВП и основой адекватного лечения, снижения летальности является определение этиологического агента, а в случае выявления 
возбудителя бактериальной природы, определение его чувствительности к антибиотикам для дальнейшей корректировки этиотропной терапии.

Целью настоящей работы являлось сравнительное изучение этиологической структуры внебольничных пневмоний у коронапозитивных и коронанегативных больных, обратившихся за медицинской помощью в Ростовской области.

\section{Материалы и методы}

В период с 06.08.2020 г. по 23.08.2020 г. обследовано 508 больных внебольничной пневмонией, находившихся в стационарах или на амбулаторном лечении. Критерии включения в исследование: возраст старше 18 лет, установленный диагноз внебольничной пневмонии (J 18.9) согласно Российским национальным рекомендациям по внебольничной пневмонии (2019), информированное согласие пациента на участие в исследовании.

Материал для исследования: мазки из носоглотки и мокрота. Сбор, транспортирование и исследование биоматериала соответствовало требованиям нормативной документации МР 4.2.0114-16 и МУК 4.2.3115-13.

Верификация респираторных вирусов, включая PHK SARS-CoV-2, а также $M$. pneumoniae, C. pneumoniae, L. pneumophila выполнена методом полимеразной цепной реакции в мазках носоглотки $(\mathrm{n}=508)$. Сравнительный анализ результативности обнаружения PHK SARS-CoV-2 проведен путем параллельного ПЦР исследования мазков носоглотки и мокроты $(\mathrm{n}=406)$. Исследование клинического материала осуществляли при помощи коммерческих наборов реагентов: «РИБО-преп», «Реверта-L», «АмплиСенс ОРВИ-скринFL», «АмплиСенс Influenza virus A/B-FL», «АмплиСенс Мусорlasma pneumoniae / Chlamydophila pneumoniae-FL», «АмплиСенс Legionella pneumophila-FL», (ФБУН «ЦНИИЭ» Роспотребнадзора, Россия), Вектор-ПЦРрв-2019-nCoV-RG (ГНЦ Вектор Роспотребнадзора, Россия).

Проведено микроскопическое исследование мокроты, окрашенной по Граму (n=508), посев мокроты с определением концентрации возбудителя $(\mathrm{n}=508)$. Клинически значимыми считали микроорганизмы, выделенные из мокроты в количестве $\geq 10^{5}$ KОЕ/мл. Идентификацию выделенных штаммов бактерий осуществляли с помощью времяпролетной масс-спектрометрии на приборе Autoflex (Bruker Daltonics, Германия) с программным обеспечением BioTyper 3,0. Уровень достоверности (Score) выше 2,3 свидетельствовал о точной видовой идентификации.

Анализ данных проведен с помощью пакета статистических программ STATISTICA версия 10.0 (StatSoft Inc., США). Сравнение количественных показателей выполнено с применением критерия Стьюдента. Различия считались статистически значимыми при р < 0,05 . 


\section{Результаты и обсуждение}

На исследование поступили пробы биологического материала от 508 больных с диагнозом внебольничная пневмония (J 18.9), в том числе от женщин - 283 (55,7 \%), мужчин - 225 (44,3 \%). Возраст пациентов составлял от 21 года до 94 лет (медиана 61 год). В результате исследования показано, что частота случаев ВП увеличивается пропорционально возрасту пациентов. Так, 73,6 \% случаев ВП зарегистрировано у лиц старше 50 лет, при этом наибольшее (29,1 \%) число заболевших отмечено среди пациентов от 60 до 69 лет (табл. 1).

Таблица 1/ Table 1

Распределение по возрасту пациентов с внебольничной пневмонией

Age structure of patients with community-acquired pneumonia

\begin{tabular}{|c|c|c|c|c|c|c|c|}
\hline \multirow{2}{*}{$\begin{array}{c}\text { Возрастная } \\
\text { группа } \\
\text { Age group }\end{array}$} & \multicolumn{2}{|c|}{$\begin{array}{c}\text { SARS-CoV-2 «+» } \\
(\mathrm{n}=307)\end{array}$} & \multicolumn{2}{|c|}{$\begin{array}{c}\text { SARS-CoV-2 «-» } \\
(\mathrm{n}=201)\end{array}$} & \multicolumn{2}{|c|}{$\begin{array}{c}\text { Всего } \\
\text { Total }(n=508)\end{array}$} & \multirow{2}{*}{$\mathrm{p}$} \\
\hline & $\begin{array}{l}\text { абс. } \\
\text { abs. }\end{array}$ & $\%$ & $\begin{array}{l}\text { абс. } \\
\text { abs. }\end{array}$ & $\%$ & $\begin{array}{l}\text { абс. } \\
\text { abs. }\end{array}$ & $\%$ & \\
\hline $\begin{array}{c}\text { 18-29 лет } \\
\text { 18-29 years }\end{array}$ & 10 & 1,97 & 11 & 2,16 & 21 & 4,13 & $>0,05$ \\
\hline $\begin{array}{c}\text { 30-39 лет } \\
\text { 30-39 years }\end{array}$ & 27 & 5,31 & 14 & 2,76 & 41 & 8,07 & $>0,05$ \\
\hline $\begin{array}{c}\text { 40-49 лет } \\
\text { 40-49 years }\end{array}$ & 39 & 7,67 & 33 & 6,50 & 72 & 14,17 & $>0,05$ \\
\hline $\begin{array}{c}50-59 \text { лет } \\
50-59 \text { years }\end{array}$ & 58 & 11,42 & 45 & 8,85 & 103 & 20,27 & $>0,05$ \\
\hline $\begin{array}{l}\text { 60-69 лет } \\
\text { 60-69 years }\end{array}$ & 91 & 17,91 & 57 & 11,22 & 148 & 29,13 & $>0,05$ \\
\hline $\begin{array}{c}>70 \text { лет } \\
>70 \text { years }\end{array}$ & 82 & 16,14 & 41 & 8,07 & 123 & 24,21 & $>0,05$ \\
\hline $\begin{array}{l}\text { Всего } \\
\text { Total }\end{array}$ & 307 & 60,43 & 201 & 39,57 & 508 & 100 & $<0,01$ \\
\hline
\end{tabular}

Примечание: $\mathrm{n}$ - количество наблюдений; p - статистическая значимость различий в группах SARS-CoV-2 «+» и SARS-CoV-2 «-»

Среди обследованных 412 (81,1%) пациентов госпитализированы в медицинские организации г. Ростова-на-Дону, 96 (18,9 \%) - находились на амбулаторном лечении. Наибольшее число (69,9 \%) госпитализаций пациентов пришлось на 3-10 сутки после начала заболевания независимо от выявления SARS-CoV-2.

С целью оценки результативности обнаружения РНК нового коронавируса в 
зависимости от вида клинического материала параллельно были исследованы в ПЦР пробы мазков из носоглотки и мокроты у 406 пациентов (табл. 2). PHK вируса SARS-CoV-2 обнаружена в 289 (71,2 \%) образцах, из них положительный результат получен только в мазках из носоглотки в 182 (44,8 \%), только в мокроте - в 23 (5,7 \%) случаях. Вирус идентифицирован и в мазках носоглотки, и мокроте у 84 (20,7 \%) пациентов. Низкая частота выявления PHK SARS-CoV-2 в мокроте может быть обусловлена, как непродуктивным кашлем, характерным для вирусной пневмонии, так и погрешностями отбора материала. Учитывая отсутствие статистически значимых различий результатов, полученных в образцах «мазок» и «мазок + мокрота» (соответственно 266 и 289 из 406, р > 0,05), исследование мазков носоглотки на наличие PHK SARS-CoV-2 можно считать репрезентативным.

Таблица 2 / Table 2

Сравнительный анализ результативности ПЦР исследования на SARS-CoV-2 при внебольничных пневмониях

Comparative analysis of the effectiveness of PCR research on SARS-CoV-2

\begin{tabular}{|l|l|l|l|}
\hline $\begin{array}{l}\text { Вид материала } \\
\text { Туре of material }\end{array}$ & $\begin{array}{l}\text { Количество } \\
\text { исследованных } \\
\text { проб, абс. } \\
\text { Number of samples } \\
\text { еxamined, abs. }\end{array}$ & $\begin{array}{l}\text { Количество } \\
\text { положительных } \\
\text { проб, абс. } \\
\text { Number of positive } \\
\text { samples, abs. }\end{array}$ & $\begin{array}{l}\text { Доля } \\
\text { положительных } \\
\text { проб, \% } \\
\text { Percentage of } \\
\text { positive samples, } \\
\%\end{array}$ \\
\hline $\begin{array}{l}\text { Мазок из носоглотки } \\
\text { А swab from the nasopharynx }\end{array}$ & 406 & 266 & 65,5 \\
\hline $\begin{array}{l}\text { Мокрота } \\
\text { Sputum }\end{array}$ & 406 & 107 & 26,4 \\
\hline $\begin{array}{l}\text { Мазки+мокрота (хотя бы } \\
\text { один результат положителен) } \\
\text { А swab+ sрutum (аt lеаst оnе } \\
\text { result is розіtive) }\end{array}$ & 406 & 289 & 71,2 \\
\hline
\end{tabular}

Примечание: статистическая значимость различий в группах

a) «мазок из носоглотки» и «мокрота» $(\mathrm{p}<0,01)$;

б) «мазок из носоглотки» и «мазки+мокрота» $(\mathrm{p}>0,05)$;

в) «мокрота» и «мазки+мокрота» $(\mathrm{p}<0,01)$.

Общее число пациентов с положительным тестом на SARS-CoV-2 составило 307 из 508 исследованных (60,4 \%). Доля COVID-19 больных колебалась от 47,6 \% до 66,7 \%, в зависимости от возрастной группы, однако статистически достоверных различий между ними не выявлено (р > 0,05). При этом у госпитализированных пациентов лабораторно подтвержденных случаев COVID-19 в 1,3 раза больше, чем при амбулаторном лечении (соответственно 63,3 \% и 47,9 \%, p < 0,01). В зависимости от выявления PHK SARS-CoV-2 сформированы группы исследования: 1 группа $(\mathrm{n}=307)$ - пациенты с внебольничной 
пневмонией, вирус идентифицирован (SARS-CoV-2 «+»), 2 группа (n=201) - пациенты с внебольничной пневмонией, вирус неидентифицирован (SARS-CoV-2 «-»).

Результаты исследования клинического материала на наличие других возбудителей инфекций дыхательных путей вирусной природы представлены в таблице 3. У 12,0 \% пациентов (61 чел.) были выявлены коронавирусы типов HKU-1, OC43, HL-63 или 229E (3,3\% от всех исследованных проб), риновирусы (2,4 \%), вирус парагриппа 2 типа (2, \%). Не были зарегистрированы положительные результаты при исследовании на вирус гриппа типов А и В, что связано с летним сезоном. Среди пациентов с положительным результатом на SARS-CoV-2 вирусные микст-инфекции обнаружены у 31 (10,1 \%) пациента. В группе с отрицательным результатом на SARS-CoV-2 доля проб с установленным возбудителем вирусной этиологии составила 30 (14,9 \%). Статистически достоверных различий в обнаружении респираторных вирусов у пациентов SARS-CoV-2 «+» и SARS-CoV-2 «-» не выявлено (р > 0,05). Однако обращает на себя внимание тот факт, что у 25 (8,1 \%) пациентов SARS-CoV-2 «+» выявлена ассоциация двух, у 5 (1,6 \%) пациентов - трех, в одном случае четырех этиологических агентов вирусной природы. Преимущественно зарегистрирована микст-инфекция «SARS-CoV-2+риносинцитиальный вирус», «SARS-CoV-2+коронавирус других типов» (по 6 пациентов). При внебольничных пневмониях с отрицательным результатом на SARS-CoV-2 одновременное сочетание двух вирусных возбудителей обнаружено лишь у 4 (1,99 \%) пациентов. Таким образом, у пациентов с внебольничной пневмонией и лабораторно подтвержденным COVID-19 частота выявления инфекции полиэтиологического характера была выше. Нельзя исключить, что первоначально коронавирус выступает триггером резкой иммуносупрессии организма, на фоне которой присоединяются другие, возможно, менее агрессивные ассоцианты вирусной природы.

У 299 (58,9 \%) пациентов с внебольничной пневмонией были выявлены возбудители бактериальной и грибковой природы 36 видов (табл. 4) Наиболее частым этиологическим агентом ВП бактериальной природы являлись бактерии рода Streptococcus, которые были обнаружены у 148 (29,1 \%) пациентов, S. pneumoniae определен в качестве этиологического агента у 15 (5,4%) SARS-CoV-2 «+» и у 12 (5,5 \%) SARS-CoV-2 «-» пациентов. Среди других представителей стрептококков наиболее высокий удельный вес составили культуры $S$. viridans, выделенные у 60 (19,5 \%) пациентов с COVID-19 и у 24 (11,9 \%) пациентов с отрицательным результатом на новую кронавирусную инфекцию (р < 0,05).

Достоверно более частыми бактериальными этиологическими агентами ВП у пациентов с отрицательным результатом исследования на SARS-CoV-2 были S. mitis, S. oralis, S. salivarius, S. parasanguinis, Rothia mucilaginosa, Neisseria meningitidis, $N$. mucosa. 
Этиологический спектр возбудителей вирусной природы

Etiological spectrum of viral pathogens

\begin{tabular}{|c|c|c|c|c|c|c|c|}
\hline \multirow[b]{2}{*}{$\begin{array}{l}\text { Возбудитель } \\
\text { Pathogen }\end{array}$} & \multicolumn{2}{|c|}{$\begin{array}{l}\text { SARS-CoV-2 «+» } \\
(\mathrm{n}=307)\end{array}$} & \multicolumn{2}{|c|}{$\begin{array}{l}\text { SARS-CoV-2 «-» } \\
(\mathrm{n}=201)\end{array}$} & \multicolumn{2}{|c|}{$\begin{array}{c}\text { Всего } \\
(n=508)\end{array}$} & \multirow{2}{*}{$\mathrm{p}$} \\
\hline & $\begin{array}{l}\text { aбс. } \\
\text { abs. }\end{array}$ & $\%$ & $\begin{array}{l}\text { aбc. } \\
\text { abs. }\end{array}$ & $\%$ & $\begin{array}{l}\text { aбc. } \\
\text { abs. }\end{array}$ & $\%$ & \\
\hline $\begin{array}{l}\text { PHK коронавируса (HKU- } \\
\text { 1,OC43, HL-63 или 229E) }\end{array}$ & 9 & 2,9 & 8 & 4,0 & 17 & 3,3 & $>0,05$ \\
\hline $\begin{array}{l}\text { PHK риновируса } \\
\text { RNA of rhinovirus }\end{array}$ & 4 & 1,3 & 8 & 4,0 & 12 & 2,4 & $>0,05$ \\
\hline $\begin{array}{l}\text { PHK вируса парагриппа } 2 \text { типа } \\
\text { RNA of type } 2 \text { parainfluenza virus }\end{array}$ & 5 & 1,6 & 5 & 2,5 & 10 & 2,0 & $>0,05$ \\
\hline $\begin{array}{l}\text { PHK PC-вируса } \\
\text { RNA of RS-virus }\end{array}$ & 7 & 2,3 & 2 & 1,0 & 9 & 1,8 & $>0,05$ \\
\hline $\begin{array}{l}\text { PHK бокавируса } \\
\text { RNA bocavirus }\end{array}$ & 6 & 2,0 & 3 & 1,5 & 9 & 1,8 & $>0,05$ \\
\hline $\begin{array}{l}\text { PHK вируса парагриппа } 3 \text { типа } \\
\text { RNA of type } 3 \text { parainfluenza virus }\end{array}$ & 4 & 1,3 & 5 & 2,5 & 9 & 1,8 & $>0,05$ \\
\hline $\begin{array}{l}\text { PHK вируса парагриппа } 1 \text { типа } \\
\text { RNA of type } 1 \text { parainfluenza virus }\end{array}$ & 2 & 0,7 & 2 & 1,0 & 4 & 0,8 & $>0,05$ \\
\hline $\begin{array}{l}\text { PHK метапневмовируса } \\
\text { RNA of Metapneumovirus }\end{array}$ & 2 & 0,7 & 1 & 0,5 & 3 & 0,6 & $>0,05$ \\
\hline $\begin{array}{l}\text { PHK аденовируса } \\
\text { Adenovirus RNA }\end{array}$ & 0 & 0 & 0 & 0 & 0 & 0 & $>0,05$ \\
\hline $\begin{array}{l}\text { PHK вируса парагриппа } 4 \text { типа } \\
\text { RNA of type } 4 \text { parainfluenza virus }\end{array}$ & 0 & 0 & 0 & 0 & 0 & 0 & $>0,05$ \\
\hline $\begin{array}{l}\text { PHK вируса гриппа А } \\
\text { RNA of Influenza virus A }\end{array}$ & 0 & 0 & 0 & 0 & 0 & 0 & $>0,05$ \\
\hline $\begin{array}{l}\text { PHK вируса гриппа В } \\
\text { RNA of Influenza virus B }\end{array}$ & 0 & 0 & 0 & 0 & 0 & 0 & $>0,05$ \\
\hline Всего & 39 & 12,7 & 34 & 16.9 & 73 & 14,4 & $>0,05$ \\
\hline
\end{tabular}

Примечание: $\mathrm{n}$ - количество наблюдений; $\mathrm{p}$ - статистическая значимость различий в группах SARS-CoV-2 «+» и SARS-CoV-2 «-»

B обеих группах пациентов (SARS-CoV-2 «+» и SARS-CoV-2 «-») в небольшом количестве случаев с помощью бактериологического метода изолировали различные плазмокоагулирущие (S. aureus) и некоагулирущие (S. epidermidis) стафилококки. Однако обращает на себя внимание тот факт, что если у коронанегативных больных стафилококковое поражение легких (S. aureus) сопровождалось по данным микроскопии выраженным нейтрофильным лейкоцитозом, то у коронапозитивных больных наблюдалось отсутствие какой-либо лейкоцитозной реакции. Эта закономерность зарегистрирована и в случае выявления других бактериальных возбудителей - K pneumoniae, P. aeruginosa и др. Это еще раз свидетельствует в пользу того, что коронавирус резко подавляет иммунную систему макроорганизма. 
Этиологически значимые микроорганизмы, изолированные из мокроты больных внебольничными пневмониями

Etiologically significant microorganisms isolated from sputum of patients with community-acquired pneumonia

\begin{tabular}{|c|c|c|c|c|c|c|c|c|}
\hline \multirow{2}{*}{\multicolumn{2}{|c|}{ Вид микроорганизма }} & \multicolumn{2}{|c|}{$\begin{array}{c}\text { Всего } \\
(n=508) \\
\end{array}$} & \multicolumn{2}{|c|}{$\begin{array}{c}\text { SARS-CoV-2 } \\
«+»(n=307)\end{array}$} & \multicolumn{2}{|c|}{$\begin{array}{c}\text { SARS-CoV-2 } \\
«-»(n=201)\end{array}$} & \multirow[t]{2}{*}{$\mathrm{p}$} \\
\hline & & абс. & $\%$ & абс. & $\%$ & абс. & $\%$ & \\
\hline \multirow[t]{9}{*}{ Streptococcus } & pneumoniae & 28 & 5,5 & 17 & 5,4 & 12 & 5,5 & $>0,05$ \\
\hline & viridans & 84 & 16,5 & 60 & 19,5 & 24 & 11,9 & $<0,05$ \\
\hline & acidominimus & 1 & 0,2 & 0 & 0 & 1 & 0,5 & $>0,05$ \\
\hline & agalactiae & 1 & 0,2 & 0 & 0 & 1 & 0,5 & $>0,05$ \\
\hline & infantis & 1 & 0,2 & 0 & 0 & 1 & 0,5 & $>0,05$ \\
\hline & mitis & 8 & 1,6 & 0 & 0 & 8 & 4,0 & $<0,01$ \\
\hline & oralis & 8 & 1,6 & 0 & 0 & 8 & 4,0 & $<0,01$ \\
\hline & salivarius & 11 & 2,2 & 0 & 0 & 11 & 5,5 & $<0,001$ \\
\hline & parasanguinis & 6 & 1,2 & 0 & 0 & 6 & 3,0 & $<0,01$ \\
\hline \multirow[t]{6}{*}{ Candida } & albicans & 86 & 16,9 & 62 & 20,2 & 24 & 11,9 & $<0,05$ \\
\hline & krusei & 4 & 0,8 & 4 & 1,3 & 0 & 0,0 & $>0,05$ \\
\hline & kefir & 1 & 0,2 & 0 & 0 & 1 & 0,5 & $>0,05$ \\
\hline & tropicalis & 21 & 4,1 & 16 & 5,2 & 5 & 2,5 & $>0,05$ \\
\hline & guilliermondii & 1 & 0,2 & 1 & 0,3 & 0 & 0,0 & $>0,05$ \\
\hline & lusitaniae & 1 & 0,2 & 0 & 0,0 & 1 & 0,5 & $>0,05$ \\
\hline \multicolumn{2}{|c|}{ Geotrichum capitatum } & 2 & 0,4 & 2 & 0,7 & 0 & 0,0 & $>0,05$ \\
\hline \multirow{7}{*}{ Neisseria } & meningitidis & 5 & 1,0 & 0 & 0 & 5 & 2,5 & $<0,01$ \\
\hline & flavescens & 26 & 5,1 & 11 & 3,6 & 15 & 7,5 & $>0,05$ \\
\hline & subflavescens & 6 & 1,2 & 5 & 1,6 & 1 & 0,5 & $>0,05$ \\
\hline & flava & 1 & 0,2 & 1 & 0,3 & 0 & 0,0 & $>0,05$ \\
\hline & subflava & 1 & 0,2 & 1 & 0,3 & 0 & 0,0 & $>0,05$ \\
\hline & sicca & 4 & 0,8 & 3 & 1,0 & 1 & 0,5 & $>0,05$ \\
\hline & mucosa & 3 & 0,6 & 0 & 0 & 3 & 1,5 & $<0,05$ \\
\hline Rothia & mucilaginosa & 16 & 3,2 & 3 & 1,0 & 13 & 6,5 & $<0,01$ \\
\hline \multirow[t]{4}{*}{ Staphylococcus } & aureus & 51 & 10,0 & 36 & 11,7 & 15 & 7,5 & $>0,05$ \\
\hline & capitis & 2 & 0,4 & 0 & 0 & 2 & 1,0 & $>0,05$ \\
\hline & epidermidis & 2 & 0,4 & 0 & 0 & 2 & 1,0 & $>0,05$ \\
\hline & haemolitycus & 4 & 0,8 & 0 & 0 & 4 & 2,0 & $<0,05$ \\
\hline \multicolumn{2}{|c|}{ Escherichia coli } & 6 & 1,2 & 6 & 2,0 & 0 & 0,0 & $<0,05$ \\
\hline \multicolumn{2}{|c|}{ Enterococcus faecalis } & 9 & 1,8 & 5 & 1,6 & 4 & 2,0 & $>0,05$ \\
\hline \multicolumn{2}{|c|}{ Stenotrophomonas maltophilia } & 2 & 0,4 & 1 & 0,3 & 1 & 0,5 & $>0,05$ \\
\hline \multicolumn{2}{|c|}{ Pseudomonas aeruginosa } & 2 & 0,4 & 1 & 0,3 & 1 & 0,5 & $>0,05$ \\
\hline \multirow[t]{2}{*}{ Klebsiella } & pneumoniae & 10 & 2,0 & 5 & 1,6 & 5 & 2,5 & $>0,05$ \\
\hline & oxytoca & 3 & 0,6 & 1 & 0,3 & 2 & 1,0 & $>0,05$ \\
\hline \multicolumn{2}{|l|}{ M. pneumoniae } & 1 & 0,2 & 1 & 0,3 & 0 & 0 & $>0,05$ \\
\hline \multicolumn{2}{|l|}{ C. pneumoniae } & 1 & 0,2 & 1 & 0,3 & 0 & 0 & $>0,05$ \\
\hline
\end{tabular}

Примечание: $\mathrm{n}$ - количество наблюдений; $\mathrm{p}$ - статистическая значимость различий в группах SARS-CoV-2 «+» и SARS-CoV-2 «-» 
Согласно имеющимся в нашем распоряжении данным, лечение антибактериальными препаратами на момент обследования проводилось у 29 \% пациентов. Возможно, на фоне антибиотикотерапии у 86 (16,9 \%) пациентов выделены дрожжи p. Candida в диагностических количествах $\left(\geq 10^{4}\right)$. У коронапозитивных больных дрожжевая микрофлора выявлена в 20,2 \% случаев, у коронанегативных больных - 11,9 \% (р < 0,05).

Не выявлено зависимости удельного веса пациентов с микст-инфекциями от дня госпитализации после начала заболевания. Отсутствовали различия в спектре вирусных или бактериальных этиологических агентов в зависимости от продолжительности болезни. В то же время у пациентов с отрицательным результатом на SARS-CoV-2 обнаружен более широкий спектр представителей патогенной и условно-патогенной бактериальной микрофлоры во всех возрастных группах. Также наблюдалось увеличение числа внебольничных пневмоний, вызванных пневмококком, в возрастных группах старше 40 лет. Доля пациентов с микст-инфекцией достоверно не отличалась среди пациентов, находящихся на амбулаторном и стационарном лечении (соответственно 58,3 \% и 58,5 \%; р > $0,05)$.

Таким образом, проведенное исследование показало, что на фоне иммуносупрессии, вызванной коронавирусной инфекцией, организм человека становится уязвимым для активизации условно патогенной микрофлоры и развития вторичных осложнений бактериального или вирусного генеза.

\section{Заключение}

В период распространения новой коронавирусной инфекции в Ростовской области основным этиологическим агентом внебольничных пневмоний является новый коронавирус SARS-CoV-2. Особенностью ВП у пациентов с лабораторно подтвержденным COVID-19 является более высокая частота микст-инфекций как вирусной, так и бактериальной этиологии.

На фоне выявления у пациентов с ВП PHK SARS-CoV-2 зарегистрированы случаи обнаружения коронавирусов других типов (HKU-1,OC43, HL-63 или 229E).

Наиболее часто этиологическим агентом ВП бактериальной природы у пациентов являлись бактерии рода Streptococcus как у пациентов с ВП, ассоциированной с COVID-19, так и пациентов с отрицательным результатом на SARS-CoV-2.

Коронавирусные больные представляют группу высокого риска по развитию микотических поражений легких, возможно на фоне лечения антибактериальными препаратами. 
Конфликт интересов. Авторы подтверждают отсутствие конфликта финансовых/нефинансовых интересов, связанных с написанием статьи.

\section{Список литературы}

1. Чучалин А.Г., Синопальников А.И., Козлов Р.С., Тюрин И.Е., Рачина С.А. Клинические рекомендации по диагностике, лечению и профилактике тяжелой внебольничной пневмонии у взрослых. Клиническая микробиология и антимикробная химиотерапия. 2015. Т. 17. № 2. С. 84-126.

2. Статистические материалы Федеральной службы по надзору в сфере защиты прав потребителей и благополучия человека (Форма 2). Москва, 2019.

3. Рачина С.А., Бобылев А.А. Атипичные возбудители внебольничной пневмонии: от эпидемиологии к особенностям диагностики и лечения. Практическая пульмонология. 2016; 2:20-27.

4. Рачина С.А., Иванчик Н.В., Козлов Р.С. Особенности микробиологической диагностики при внебольничной пневмонии у взрослых. Практическая пульмонология. 2016; 4:40-47.

5. Du Toit A. Measles increases the risk of other infections. Nat. Rev. Microbiol. 2019; 18:2. DOI: 10.1038/s41579-019-0301-7

6. Zahariadis G., Gooley T.A., Ryall P., Hutchinson C., Latchford M.I., Fearon M.A., et al. Risk of ruling out severe acute respiratory syndrome by ruling in another diagnosis: variable incidence of atypical bacteria coinfection based on diagnostic assays. Canc Respir J. 2006; 13:1722. DOI: $10.1155 / 2006 / 862797$

7. Arabi Y.M., Al-Omari A., Mandourah Y., Al-Hameed F., Sindi A.A., Alraddadi B., et al. Critically ill patients with the Middle East Respiratory Syndrome: a multicenter retrospective cohort study. Crit Care Med. 2017; 45:1683-1695. DOI: 10.1097/CCM.0000000000002621.

8. Zhou Y., Guo S., He Y., Zuo Q., Liu D., Xiao M., Fan J., Li X. COVID-19 Is Distinct From SARS-CoV-2-Negative Community-Acquired Pneumonia. Front. Cell. Infect. Microbiol. 2020; https://doi.org/10.3389/fcimb.2020.00322

9. Chih-Cheng Lai, Cheng-Yi, Wang Po-Ren Hsueh. Co-infections among patients with COVID-19: The need for combination therapy with non-anti-SARS-CoV-2 agents? Journal of Microbiology, Immunology and Infection Volume. 2020; 53:505-512

10. Chen N., Zhou M., Dong X., Qu J., Gong F., Han Y., et al. Epidemiological and clinical characteristics of 99 cases of 2019 novel coronavirus pneumonia in Wuhan, China: a descriptive study. LANCET. 2020; 395:507-513 DOI: 10.1016/S0140-6736(20)30211-7. 
11. Стулова М.В., Кудряшева И.А., Полунина О.С., Черенова Л.П., Аршба Т.Е., Лисина О.А., Казакова Е.А. Сравнительный клинико-лабораторный анализ COVID-19 ассоциированной пневмонии с внебольничной пневмонией бактериальной этиологии. Современные проблемы науки и образования. 2020; 3. DOI: 10.17513/spno.29905

\section{References}

1. Chuchalin A. G., Sinopalnikov A. I., Kozlov R. S., Tyurin I. E., Rachina S. A. Community-acquired pneumonia in adults: practical recommendations for diagnosis, treatment and prevention. Manual for doctors. Clinical Microbiology and antimicrobial chemotherapy. 2010; 12(3):186-225.

2. Statistical materials of the Federal Service for Supervision of Consumer Rights Protection and Human Welfare (Form 2). Moscow, 2019.

3. Rachina S. A., Bobylev A. A. Atypical pathogens of community-acquired pneumonia: from epidemiology to features of diagnosis and treatment. Practical pulmonology. 2016; 2:20-27. No DOI

4. Rachina S. A., Ivanchik N. V., Kozlov R. S. Features of microbiological diagnostics in community-acquired pneumonia in adults. Practical pulmonology. 2016; 4:40-47. No DOI

5. Du Toit A. Measles increases the risk of other infections. Nat. Rev. Microbiol. 2019; 18:2. DOI: 10.1038/s41579-019-0301-7

6. Zahariadis G., Gooley T.A., Ryall P., Hutchinson C., Latchford M.I., Fearon M.A., et al. Risk of ruling out severe acute respiratory syndrome by ruling in another diagnosis: variable incidence of atypical bacteria coinfection based on diagnostic assays. Canc Respir J. 2006; 13:1722. DOI: $10.1155 / 2006 / 862797$

7. Arabi Y.M., Al-Omari A., Mandourah Y., Al-Hameed F., Sindi A.A., Alraddadi B., et al. Critically ill patients with the Middle East Respiratory Syndrome: a multicenter retrospective cohort study. Crit Care Med. 2017; 45:1683-1695. DOI: 10.1097/CCM.0000000000002621

8. Zhou Y., Guo S., He Y., Zuo Q., Liu D., Xiao M., Fan J., Li X. COVID-19 Is Distinct From SARS-CoV-2-Negative Community-Acquired Pneumonia. Front. Cell. Infect. Microbiol. 2020; https://doi.org/10.3389/fcimb.2020.00322

9. Chih-Cheng Lai, Cheng-Yi, Wang Po-Ren Hsueh. Co-infections among patients with COVID-19: The need for combination therapy with non-anti-SARS-CoV-2 agents? Journal of Microbiology, Immunology and Infection Volume. 2020; 53:505-512 
10. Chen N., Zhou M., Dong X., Qu J., Gong F., Han Y., et al. Epidemiological and clinical characteristics of 99 cases of 2019 novel coronavirus pneumonia in Wuhan, China: a descriptive study. LANCET. 2020; 395:507-513 DOI: 10.1016/S0140-6736(20)30211-7

11. Stulova M. V., kudryasheva I. A., Polunina O. S., Cherenova L. P., Arshba T. E., Lisina O. A., Kazakova E. A. Comparative clinical and laboratory analysis of COVID-19 associated pneumonia with community-acquired pneumonia of bacterial etiology. Modern problems of science and education. 2020; 3. DOI: 10.17513/spno.29905 


\section{FEATURES OF ETIOLOGY OF COMMUNITY-ACQUIRED PNEUMONIA ASSOCIATED WITH COVID-19}

A.Yu. Popova ${ }^{1,2}$, E.B. Ezhlova ${ }^{1}$, Yu.V. Demina ${ }^{1,2}$, A.K. Noskov ${ }^{3}$, E.V. Kovalev' ${ }^{4}$ O.S. Chemisova ${ }^{3}$, T.I. Tverdokhlebova ${ }^{5}$, N.V. Pavlovich ${ }^{3}$, S.O. Vodop yanov $^{3}$, M.V. Tsimbalistova ${ }^{3}$, S.V. Volovikova $^{3}$, S.I. Stenina ${ }^{3}$, E.N. Gudueva ${ }^{3}$, M.M. Sagakyanc ${ }^{3}$, A.V. Aleshukina ${ }^{5}$, S.S. Slis ${ }^{4}$

${ }^{1}$ Federal Service for Surveillance on Consumer’ Rights Protection and Human Welfare, Moscow, Russian Federation

${ }^{2}$ Russian Medical Academy of Continuing Professional Education, Moscow, Russian Federation

${ }^{3}$ Federal Service for Surveillance in the Sphere of Consumers Rights Protection and Human Welfare, the Federal Government Health Institution Rostov-on-Don Plague Control Researsh Institute, Rostov-on-Don, Russian Federation

${ }^{4}$ Department Federal Service for Surveillance on Consumer Rights Protection and Human Welfare for the Rostov region, Rostov-on-don, Russian Federation

${ }^{5}$ Federal research institute of Microbiology and Parasitology of Rospotrebnadzor, Rostovon-Don, Russian Federation

\section{Summary}

The results of the etiological agents study of bacterial and viral nature in patients diagnosed with community-acquired pneumonia associated with COVID-19 are presented. During the spread of a new coronavirus infection in the Rostov region, the main etiological agent of communityacquired pneumonia is the new SARS-CoV-2 coronavirus. A feature of pneumonia in patients with laboratory-confirmed COVID-19 is a higher incidence of mixed infection of both viral and bacterial etiology. Against the background of detection of a new coronavirus infection in patients with pneumonia, cases of detection of other types of coronaviruses have been registered (HKU-1,OC43, HL-63 and 229E). The most common etiological agent of bacterial pneumonia in patients was Streptococcus spp., both in patients with COVID-19-associated pneumonia and in patients who tested negative for SARS-CoV-2.

Key words: COVID-19, community-acquired pneumonia, types of bacteria, respiratory viruses, Rostov region.

Conflict of interest: The authors declare no conflict of interest.

Corresponding author: Aleksey K. Noskov, e-mail: noskov-epid@mail.ru. 